\title{
Patients' Diverse Beliefs about What Happens at the Time of Death
}

\author{
Henry S. Perkins, MD ${ }^{1 \star}$, Josie D. Cortez, MA², Helen P. Hazuda, PhD ${ }^{1,3}$
}

${ }^{1}$ Department of Medicine, The University of Texas Health Science Center, San Antonio, Texas; 2Intercultural Development Research Association, San Antonio, Texas; ${ }^{3}$ Research Service, Department of Veterans Affairs Audie L. Murphy Medical Center, San Antonio, Texas.

BACKGROUND: Beliefs about what happens at the time of death surely affect a patient's whole dying experience and could help guide end-of-life care. Yet virtually no research describes those beliefs. This exploratory study begins the descriptive process.

METHODS: Assuming culture is key, we interviewed 26 Mexican-American (MA), 18 Euro-American (EA), and 14 African-American (AA) inpatients about their beliefs concerning what happens at the time of death.

RESULTS: One belief, that death separates the dead from the living, was widespread. Majorities of all 3 ethnic group samples and of 5 of the 6 gender subsamples expressed this belief, saying the dead "go" or "leave" from this life. Other beliefs differed by ethnic group or gender. For example, more EAs (50\%) than others said death is a momentary event, and more MAs (35\%) than others said death involves "being taken" by an external force (always God or Jesus). Furthermore, considerably more EA women $(45 \%)$ than others said some senses persist after death. In contrast, the physiologic signs that participants cited as defining the exact time of death varied from individual to individual with no ethnic or gender pattern, and no one sign predominated.

CONCLUSIONS: A few beliefs about what happens at the time of death may characterize Americans in general; many other beliefs may characterize only certain ethnic groups, genders, or individuals. To identify such beliefs and to use them to guide end-of-life care, hospitalists and other health professionals may have to elicit them directly from patients or survivors. Journal of Hospital Medicine 2012;7:110-116. (c) 2011 Society of Hospital Medicine
Every health professional bears responsibility at some point for helping dying patients and their survivors face death spiritually and emotionally. But, because most Americans die in hospitals, that responsibility falls disproportionately to hospitalists and other hospital-based health professionals.

Personal beliefs about what happens at death surely influence whether patients welcome or dread it, and whether survivors remember it with relief or regret. ${ }^{1}$ We believe, therefore, that competent, compassionate end-of-life care requires hospitalists and other health professionals who attend dying patients to address such beliefs. But people do not readily volunteer them, health professionals rarely elicit them, and little research describes them.

We, therefore, performed a large exploratory study to begin characterizing patients' beliefs about what

\footnotetext{
*Address for correspondence: Dr. Perkins is a member of the Division of General Medicne, Department of Medicine, The University of Texas Health Science Center, PO Box 1696, Dearborn, MI 48121-1696; Fax: 313-722-4689; E-mail: perkins@uthscsa.edu

Additional Supporting Information may be found in the online version of this article.

Received: December 22, 2010; Revised: March 26, 2011; Accepted: May 7, 2011

2011 Society of Hospital Medicine DOI 10.1002/jhm.947

Published online in Wiley Online Library (Wileyonlinelibrary.com).
}

happens at the time of death. We assumed that culture-the values a group uses to interpret shared experiences and transmits across generations $s^{2,3}$-influences those beliefs. ${ }^{1,4-10}$ We reasoned that, because death is a universal human experience, every culture must address its meaning. ${ }^{5}$ Prior studies showing ethnic cultural differences over advance care planning, life support, and other aspects of dying further supported our assumption. ${ }^{3,8,10-12}$

Our interview study revealed occasional beliefs that may characterize Americans in general, some beliefs that may characterize only certain ethnic groups or genders, and many beliefs that may characterize only particular individuals.

\section{METHODS}

We constructed a semistructured interview, based on topics and questions from the end-of-life literature and our own encounters with dying patients and their survivors. The interview schedule covered topics such as the right time to die, what happens at death, and the afterlife. We pretested all questions before using them in interviews.

Study participants were older inpatients from the 3 largest American ethnic groups-Mexican Americans (MAs), Euro-Americans (EAs), and African Americans (AAs), ${ }^{13}$ as identified by a validated ethnic algorithm. ${ }^{14}$ We reasoned that age, current serious (though not necessarily terminal) illness, and having 


\begin{tabular}{|c|c|c|c|}
\hline Characteristics & $\begin{array}{l}\text { Mexican Americans } \\
\text { (26 Total: } 14 \text { Men, } \\
12 \text { Women) }\end{array}$ & $\begin{array}{l}\text { Euro-Americans } \\
\text { (18 Total: } 7 \text { Men, } \\
11 \text { Women) }\end{array}$ & $\begin{array}{l}\text { African Americans } \\
\text { (14 Total: } 7 \text { Men, } \\
7 \text { Women) }\end{array}$ \\
\hline \multicolumn{4}{|l|}{ Age (years) } \\
\hline Mean & 63 & 63 & 59 \\
\hline $\begin{array}{l}\text { Standard deviation } \\
\text { Religion, \% }\end{array}$ & \pm 8.5 & \pm 8.4 & \pm 5.8 \\
\hline Roman Catholic & 77 & 39 & 0 \\
\hline Protestant & 15 & 50 & 93 \\
\hline Other & 8 & 11 & 7 \\
\hline \multicolumn{4}{|l|}{ Education (years) } \\
\hline Median & 7 & 12 & 11 \\
\hline Interquartile range & $3-11$ & $10-12$ & $10-12$ \\
\hline Currently married, \% & 58 & 33 & 29 \\
\hline
\end{tabular}

experienced the deaths of others had already prompted these older inpatients to think about death. ${ }^{11}$

Admission logs from 2 San Antonio, Texas, hospitals identified all patients, aged 50 to 79 , who were admitted over a 9-month period for any of $10 \mathrm{com}-$ mon internal medicine diagnoses. From these logs we selected interviewees by "purposive" sampling, a nonstatistical technique that ensured adequate participant numbers by ethnic group and gender. ${ }^{15,16}$ We invited patients to interview only after their primary physicians gave permission.

Sixty of 65 participants who began interviews completed them, and 58 of the 60 could be classified into 1 of the 3 ethnic groups. ${ }^{14}$ These 58 , who produced saturation for all themes mentioned by more than $5 \%$ of participants, constituted our analysis sample. Participants included 26 MAs (14 men, 12 women), 18 EAs ( 7 men, 11 women), and 14 AAs ( 7 men, 7 women). The most prevalent admitting diagnoses were congestive heart failure (19 participants), angina (17 participants), and pneumonia and chronic obstructive pulmonary disease (5 participants each). The 3 ethnic group samples had similar mean ages but differed in other ways (Table 1). MAs were typically Roman Catholic, educated through grade 7, and married; EAs were divided between Roman Catholic and Protestant, educated through grade 12, and mostly unmarried; and AAs were nearly all Protestant, educated through grade 11, and mostly unmarried. The genders within each ethnic group sample were similar by age, religion, and education (data not shown). AA men and women were also similar by marital status. However, MAs and EAs had more men than women who were married, and more women than men who were widowed.

Two trained, bilingual women-1 MA and $1 \mathrm{EA}$, not specifically matched to participants by ethnic group-used the schedule of questions to interview participants. The interviews usually took place 3 days after admission, involved one-on-one engage- ment in participants' hospital rooms, were audiotaped, and lasted roughly 90 minutes. Most questions were open-ended, allowing participants to express beliefs in their own words. For example, the open-ended question, "What do you think happens at the end of a person's life?" introduced the topic covered here. To help focus responses, interviewers asked participants early on to name the closest person to them to have died. Interviewers then encouraged participants to describe their beliefs specifically in terms of that person's death. (We assumed the closeness of the relationships had kept those deaths vivid for participants even years afterward.) Most participants responded by referring to that person, but a few described their own "death-like" experiences or their general beliefs about death. Interviewers probed as necessary to clarify responses.

Participants interviewed in Spanish or English as they preferred. Two MAs interviewed entirely in Spanish, 10 MAs interviewed partly in Spanish and partly in English, and all other participants interviewed entirely in English. Bilingual typists transcribed the audiotapes, translating any Spanish into English. Two bilingual experts independently confirmed the accuracy of the translations.

The coders who content-analyzed responses varied by ethnic group, gender, and professional training. They conducted their analysis in 4 steps, each involving initial, independent, blinded reviews by 2 coders; comparison of interpretations; and consensual resolution of disagreements. First, 2 coders deleted any comments irrelevant to death or dying. Second, the same coders assembled the remaining passages by topic, such as beliefs about what happens at the time of death. Third, 1 original coder and a senior investigator naive to the responses identified themes within each topic. Fourth, that original coder and either of 2 new coders determined for each interview the presence or absence of each theme. Theme presence required agreement between the original coder and the new coder or, when they differed, agreement between one of these coders and an independent adjudicator. Lastly, the 3 authors aggregated themes into meaningful categories by consensus, and checked these categories for trustworthiness against participants' original comments.

We report the results for each theme primarily as the percentages of participants within these ethnic group or gender samples who mentioned the theme. Though content analyses are usually reported qualitatively, percentages have 2 advantages here. ${ }^{17}$ First, readers can see the percentages and judge for themselves the important similarities, differences, and patterns in the data. Second, percentages enable researchers to formulate their own questions for further study, say, questions based on the largest percentages or largest percentage differences in the data. We also 
report representative quotes to illustrate the depth and richness of participant responses.

The study complied with all institutional review board requirements.

\section{RESULTS}

Most participants in all 3 ethnic group samples named a parent as the closest person to them to have died (Table 2). Among these participants, MAs named their mothers overwhelmingly, but EAs and AAs named their mothers and fathers nearly equally. Other participants named siblings, children, other relatives, or friends. Of 13 widowed participants, only 4 named their spouses.

Thirty-nine participants-20 MAs, 13 EAs, and 6 AAs-described the closest person's time of death as either momentary (typically less than a minute) or prolonged (longer than a few minutes). More EAs described it as momentary than as prolonged $(50 \%$ vs

\begin{tabular}{|c|c|c|c|}
\hline Characteristic & $\begin{array}{l}\text { Mexican } \\
\text { Americans* } \\
(n=26)\end{array}$ & $\begin{array}{l}\text { Euro- } \\
\text { Americans }^{\star} \\
(\mathrm{n}=18)\end{array}$ & $\begin{array}{l}\text { African } \\
\text { Americans* } \\
(\mathrm{n}=14)\end{array}$ \\
\hline \multicolumn{4}{|l|}{ Relationship of closest person to participant $^{\dagger}$} \\
\hline Mother & 42 & 28 & 29 \\
\hline Father & 12 & 22 & 29 \\
\hline Spouse & 4 & 11 & 7 \\
\hline Other & 42 & 39 & 36 \\
\hline \multicolumn{4}{|l|}{ Closest person's death was. . } \\
\hline Momentary $y^{\ddagger}$ & 35 & 50 & 21 \\
\hline Prolonged ${ }^{\ddagger}$ & 42 & 22 & 21 \\
\hline $\begin{array}{l}\text { Participant mentioned medical treatment that } \\
\text { closest person received at time of death }\end{array}$ & 19 & 44 & 43 \\
\hline $\begin{array}{l}\text { Participant believed medical treatment caused } \\
\text { closest person to suffer at time of death }\end{array}$ & 0 & 6 & 29 \\
\hline
\end{tabular}

*Data are percentages within ethnic groups. The African Americans' percentages for the "relationship of closest person to participant" add to over $100 \%$ due to rounding. ${ }^{\dagger}$ Relationships of "other" closest persons included 4 brothers, 4 friends, 3 sons, 2 grandmothers, 2 aunts, a sister, a daughter, a grandson, an uncle, a cousin, a father-in-law, a sister-in-law, and nobody (once). ₹"Momentary" means less than a few minutes; "prolonged" means greater than a few minutes. Percentages add to less than $100 \%$ because some subjects did not give an opinion.
$22 \%)$. One EA woman said, "We were right outside [the hospital room when my father suffered his cardiac arrest]. We knew, when the alarm went off on the heart monitor, it was ... the last time we'd see him alive." In contrast, MAs and AAs split roughly equally between describing death as momentary or as prolonged (MAs: $35 \%$ and $42 \%$, respectively; AAs: $21 \%$ for both).

The ethnic group samples also differed about harm from treatments the closest person had received when dying. Of participants who specified such treatments, disproportionately more AAs (4 of 6 ) than MAs (0 of 5) or EAs (1 of 8$)$ said those treatments had caused the person to suffer at the time of death. Recalling the prolonged resuscitation efforts on his father, one AA man said that the doctors "were trying to keep him alive ... I said, 'Don't put his body through that."'

Many participants went on to describe their beliefs about what happens at the time of death, about the physiologic signs that define that time, and about the senses that persist after death.

\section{Beliefs about What Happens at the Time of Death}

Because words embody meaning, the synonyms used for "death," "dying," or "dead" give clues to people's beliefs about what happens at death. ${ }^{18}$ Fifty-three participants $(91 \%)$ used such synonyms.

Reflecting a sense of separation, the most prevalent synonyms implied movement of the dead away from this life and the living (Table 3). Forty-six participants $(79 \%)$ used one of these synonyms. Two, "goes" and "leaves," definitely implied movement but not necessarily due to an external force (theme 3A). Thirty-two participants $(55 \%)$-including majorities of all 3 ethnic group samples (range, $54 \%-57 \%$ ) and of 5 of 6 gender subsamples (range, $55 \%-64 \%$, except for $42 \%$ for MA women) - used at least one of these terms. An EA man, for example, described death as "leav[ing] this life, and ... go[ing] to the next." Other synonyms, variations on "passes" (theme 3B), may have

\begin{tabular}{|c|c|c|c|c|}
\hline The Dying Person... & Group & $\begin{array}{l}\text { Mexican Americans } \\
(26 \text { Total: } 14 \text { Men, } 12 \text { Women) } \\
(\%)^{*}\end{array}$ & $\begin{array}{l}\text { Euro-Americans } \\
(18 \text { Total: } 7 \text { Men, } 11 \text { Women) } \\
(\%)^{*}\end{array}$ & $\begin{array}{l}\text { African Americans } \\
\text { (14 Total: } 7 \text { Men, } 7 \text { Women) } \\
(\%)^{*}\end{array}$ \\
\hline \multicolumn{5}{|l|}{ A. "Goes" or "leaves" } \\
\hline & All participants & 54 & 56 & 57 \\
\hline & Men alone & 64 & 57 & 57 \\
\hline \multirow{2}{*}{\multicolumn{5}{|c|}{ B. "Passes on or away" }} \\
\hline & & & & \\
\hline & All participants & 38 & 44 & 43 \\
\hline & Men alone & 29 & 43 & 43 \\
\hline \multirow{2}{*}{\multicolumn{5}{|c|}{ C. "Is taken" }} \\
\hline & & & & \\
\hline & All participants & 35 & 6 & 21 \\
\hline & Men alone & 43 & 0 & 14 \\
\hline & Women alone & 25 & 9 & 29 \\
\hline
\end{tabular}

* Data are percentages within the groups designated in the second column from the left. Percentages for like participants-all participants, men alone, or women alone-add to more than $100 \%$ whenever some participants used more than 1 expression, and add to less than $100 \%$ when some participants used none of the expressions. 
TABLE 4. Physiologic Signs Defining the Time of Death

\begin{tabular}{|c|c|c|c|c|}
\hline Signs & Group & $\begin{array}{l}\text { Mexican Americans } \\
(26 \text { Total: } 14 \text { Men, } 12 \text { Women) } \\
(\%)^{*}\end{array}$ & $\begin{array}{l}\text { Euro-Americans } \\
\text { (18 Total: } 7 \text { Men, } 11 \text { Women) } \\
(\%)^{\star}\end{array}$ & $\begin{array}{l}\text { African Americans } \\
\text { (14 Total: } 7 \text { Men, } 7 \text { Women) } \\
(\%)^{*}\end{array}$ \\
\hline \multicolumn{5}{|c|}{ Any sign mentioned } \\
\hline & All participants & 23 & 67 & 36 \\
\hline & Men alone & 36 & 57 & 29 \\
\hline & Women alone & 8 & 73 & 43 \\
\hline \multicolumn{5}{|c|}{$\begin{array}{l}\text { Specific signs mentioned } \\
\text { A. Cessation of breathing }\end{array}$} \\
\hline & All participants & 8 & 17 & 21 \\
\hline & Men alone & 7 & 0 & 0 \\
\hline & Women alone & 8 & 27 & 43 \\
\hline \multicolumn{5}{|c|}{ B. Cessation of heartbeat } \\
\hline & All participants & 8 & 22 & 7 \\
\hline & Men alone & 14 & 14 & 14 \\
\hline & Women alone & 0 & 27 & 0 \\
\hline \multicolumn{5}{|c|}{ C. Cooling of the body } \\
\hline & All participants & 12 & 17 & 0 \\
\hline & Men alone & 21 & 0 & 0 \\
\hline & Women alone & 0 & 27 & 0 \\
\hline \multicolumn{5}{|c|}{ D. Other signs mentioned ${ }^{\dagger}$} \\
\hline & All participants & 8 & 22 & 14 \\
\hline & Men alone & 14 & 43 & 29 \\
\hline & Women alone & 0 & 9 & 0 \\
\hline
\end{tabular}

${ }^{*}$ Data are percentages within the groups designated in the second column from the left. Percentages for like participants -all participants, men alone, or women alone-add to more than the total percentages in the "any sign mentioned" rows whenever some participants cited more than 1 sign. " "Other signs" included the inability to move, speak, or recognize people indicating severe brain dysfunction (4 participants); breathing difficulties producing gurgling or gasping (2 participants); and loss of the essential "life energy," bleeding out, and the eyes' turning back into the head (1 participant each). One participant mentioned 2 of these signs.

also implied movement. Large minorities of all ethnic group samples (range, 38\%-44\%) and gender subsamples (range, 29\%-50\%) used at least one of these terms. As an MA woman said, "[W] ]e are born, and we die.... [We] stay here a while, [and then] pass through ... to the other side." Still other synonyms, variations on "taken" (theme 3C), definitely implied that an external force actively removes the dead from this life. Notably more MAs than EAs or AAs used one of these terms (35\% vs $6 \%$, and $21 \%$, respectively). All participants who did attributed the external force to God or Jesus. "We're here on borrowed time," one MA man explained. "When God tells you [that] you gotta leave ... [t]hat's when you die. He is going to take your soul."

Less prevalent synonyms for "death" carried no implication of movement and fell into 2 groups. One group included terms such as "sleeping" or "resting" that implied relief from life's struggles. Modest minorities of all ethnic group samples (range, 14\%-19\%) and of 5 of the 6 gender subsamples (range, 17\%$29 \%$, except for $0 \%$ for AA women) used such terms. Recalling his sister's death after a long illness, one MA man said, " $[\mathrm{H}]$ er soul went ... to heaven, and she's resting." The second group included terms about being "lost" to the living. Modest minorities of MAs and EAs (15\% and $11 \%$, respectively), but no AAs, used these terms. One MA woman remembered her daughter's death in childbirth, saying, Her death "took part of my life away ... [but] my grandson ... lost his mother."

\section{Beliefs about the Physiologic Signs That Define the Time of Death}

Twenty-three participants $(40 \%)$ specified physiologic signs they believed define this time (Table 4). Nineteen participants did so referring to hospital deaths; 4 participants, to home deaths. More EAs than MAs or AAs specified at least one such sign (67\% vs $23 \%$ and $36 \%$, respectively).

Seventeen of the 23 participants cited only one sign each as defining the time of death; the other 6 participants cited multiple signs. Overall, 8 physiologic signs were cited, but none predominated in any ethnic or gender group. The most common signs were cessation of breathing (theme 4A, 8 participants), cessation of heartbeat (theme 4B, 7 participants), and cooling of the body (theme 4C, 6 participants). Illustrating these signs in order, one AA woman said, "Once that breath is going out of the body ... [a person's] already dead;" an MA man said, "My mother died [as] her heart monitor kept going down little by little;" and an EA woman explained, "I didn't feel the coldness of [my dead mother in the coffin] ... she didn't belong there ... I felt like she was asleep. I was telling her to get up." Interestingly, no AAs cited cooling of the body as a sign defining the time of death. Furthermore, only 4 participants, all of whom described in-hospital deaths, cited coma or other severe brain dysfunction as such a sign.

\section{Beliefs about Senses Persisting after Death}

Of the 29 participants $(50 \%)$ who expressed opinions on this topic (Table 5), 17 said the senses definitely 
TABLE 5. Beliefs about Whether the Senses Persist after Death

\begin{tabular}{|c|c|c|c|c|}
\hline $\begin{array}{l}\text { Do the Senses } \\
\text { Persist after Death?* }\end{array}$ & Group & $\begin{array}{l}\text { Mexican Americans } \\
(26 \text { Total: } 14 \text { Men, } 12 \text { Women) } \\
(\%)^{\dagger}\end{array}$ & $\begin{array}{l}\text { Euro-Americans } \\
(18 \text { Total; } 7 \text { Men, } 11 \text { Women) } \\
(\%)^{\dagger}\end{array}$ & $\begin{array}{l}\text { African Americans } \\
\text { (14 Total: } 7 \text { Men, } 7 \text { Women) } \\
(\%)^{\dagger}\end{array}$ \\
\hline \multicolumn{5}{|l|}{ A. Definitely yes or possibly } \\
\hline & All participants & 31 & 33 & 21 \\
\hline & Men alone & 36 & 14 & 29 \\
\hline & Women alone & 25 & 45 & 14 \\
\hline \multicolumn{5}{|l|}{ B. Definitely no } \\
\hline & All participants & 23 & 11 & 29 \\
\hline & Men alone & 21 & 14 & 43 \\
\hline & Women alone & 25 & 9 & 14 \\
\hline
\end{tabular}

${ }^{*}$ All sums add to under $100 \%$ because some participants in every ethnic or gender group offered no opinion. ${ }^{\dagger}$ Data are percentages within the groups designated in the second column from the left.

TABLE 6. A Taxonomy of Possible Beliefs about Death

\begin{tabular}{lll}
\hline Level & Example(s) of Beliefs & Highest Prevalence Group(s) \\
\hline Society-wide & Death separates the dead from the living. & Americans in general \\
Particular ethnic groups & Death occurs when an external power-specifically God or Jesus_-"takes" the dead person away. & Mexican Americans \\
& Death occurs in less than a minute. & Euro-Americans \\
& Physiologic signs define the time of death. & Euro-Americans \\
Particular gender subgroups & Cooling of the body never define the time of death. & African Americans \\
Individuals & Some senses persist after death. & Euro-American women \\
& Which particular physiologic sign defines the time of death. & Idiosyncratic, no demographic pattern
\end{tabular}

or possibly persist after death (theme $5 \mathrm{~A}$ ), and 12 said they definitely do not (theme 5B). Prevalences of these contrasting beliefs differed little within ethnic group or gender samples with one exception: More EA women said the senses definitely or possibly persist after death than said they do not $(45 \%$ vs $9 \%)$.

The senses mentioned most often as persisting after death were sight ( 8 participants), hearing (7 participants), and touch (7 participants). Only 1 participant mentioned smell, and none mentioned taste. Some participants associated persistent senses with the dead person's spirit; other participants associated them with the body. All who mentioned sight associated it with the spirit. As one MA woman explained, at death the soul "is not in the body but ... lingers above ... [watching] to see how the family takes [the death]." Among those who mentioned hearing, more associated it with the spirit than with the body. Associating hearing with the spirit, one MA man said, "[W]hen I had my aneurysm ... I died three times ... I could hear music that had never been heard. It wasn't in the room ... like somebody was calling me." In contrast, an AA man insisted his dead father's "body could hear ... you." Unlike either sight or hearing, touch was associated more often with the body than with the spirit. When asked about practicing invasive procedures on the cadaver, an EA man exclaimed, "[If the doctors] hurt the guy that's dead, he ain't going to holler. ... They wouldn't know they hurt him.... [They're] liable to get back too far and hit the bone."

The large percentages of both Protestants and Roman Catholics among MAs and EAs allowed us to check religion as a potential alternative explanation for differences between ethnic groups. We found only one possible instance: In both ethnic group samples, about $50 \%$ of Protestants but only about $15 \%$ of Roman Catholics described death as momentary.

\section{DISCUSSION}

Beliefs about what happens at death surely affect the whole dying experience ${ }^{1}$ and may help guide end-of-life care. Yet for all the research on dying, the health professions literatures contain virtually no studies describing such beliefs. ${ }^{19}$ This exploratory study begins the descriptive process.

The results suggest a taxonomy-however provisional-for those beliefs (Table 6). Occasional beliefs, such as the one that death separates the dead from the living, may be held by many Americans and thereby characterize American society in general. Other beliefs may characterize only particular American ethnic groups or genders. Ethnically based beliefs may include, for MAs, the belief that death occurs when an external force, specifically God or Jesus, "takes" the dead person away; for EAs, the beliefs that death occurs in less than a minute and that physiologic signs define the time of death; and, for AAs, the belief that cooling of the body never defines the time of death. A gender-based belief may be the belief of EA women that some senses persist after death. Still other beliefs may be idiosyncratic, varying among individuals without a demographic pattern. Idiosyncratic beliefs may include which particular physiologic sign defines the time of death. 
The reader must consider these results in light of the study's assumptions, weaknesses, and strengths. Two assumptions were key: that participants expressed themselves fully (despite the difficulty of articulating such beliefs), and that the content analysts interpreted them accurately. Study weaknesses included possible conditioning of responses through prior interview questions, incomplete responsiveness about certain themes, nongeneralizability beyond these sample groups due to the purposive sampling, and educational and marital status differences as possible alternative explanations for the results. Important study strengths included the clinically important topic; the ill, older participants who had already faced death for themselves or others; the pretested, bilingual interview schedule; the open-ended questions allowing participants to express beliefs in their own words; and the rigorous content analysis.

While indicating directions for future research, our results also provide several useful lessons for current end-of-life care. First, hospitalists and other health professionals who attend the dying must not assume they can accurately predict the beliefs of patients or survivors about what happens at the time of death. Many beliefs that participants expressed here neither we nor the health professionals to whom we have presented the results could have imagined beforehand. Health professionals simply cannot expect patients and survivors to hold the same beliefs as they. Furthermore, while some beliefs may characterize certain demographic groups in general, large idiosyncratic variation within groups compromises many demographically based predictions of particular individuals' beliefs. Thus, health professionals can probably learn such beliefs only by eliciting them individual by individual. ${ }^{18}$ Admittedly awkward, the necessary inquiries ${ }^{6,20,21}$ demand courage and patience, but, when done well, may help prepare all for the death.

Second, these inquiries require health professionals to cultivate techniques for eliciting people's beliefs sensitively and accurately. ${ }^{18}$ For example, health professionals might ask questions using the same terms for death (such as "goes," "passes," or "rests") that the patient or survivors use. This technique encourages open expression of beliefs by assuring people that health professionals are listening carefully. Still, professionals must guard against misunderstandings that such terms may create-particularly by giving false hope or ignoring sad realities.

Third, armed with knowledge of patient and survivor beliefs, health professionals should tailor perimortem care accordingly. For example, because many people suffer pangs of separation at a death, health professionals should address those feelings expressly. ${ }^{22}$ Doing so may promote closure for the grieving..$^{20,23-25}$ Health professionals should also attend to beliefs such as those about the signs and duration of the time of death. As this study showed, different people may time death by different physiologic signs. The patient with a warm body but no heartbeat may be simultaneously alive to someone who sees cooling of the body as defining the time of death, and dead to someone else who sees cessation of heartbeat as doing so. ${ }^{18,26}$ Unfortunately, certain perimortem procedures, such as harvesting organs for transplantation, moving the body to the morgue, or performing an autopsy, require declaring death unambiguously at one specific time. When differences may exist over the signs or duration of death, the best way to avoid agonizing arguments or decisional paralysis when death occurs is to articulate any differences beforehand and to resolve them with a mutually acceptable management plan. ${ }^{27}$ Health professionals should also honor survivor beliefs about sentience of the dead. Unlike differences over signs and duration of death, differences over sentience of the dead may often be accommodated without definitive resolution. For example, although health professionals should treat any body respectfully, they must make special efforts to handle the dead body gently in case survivors believe it can still feel pain.

\section{CONCLUSION}

A patient's death is a climactic event for patient, survivors, and health professionals alike. It warrants careful management. Personal beliefs about what happens at death surely affect how patients anticipate it and what survivors remember of it. Compassionate perimortem care, therefore, must address those beliefs. ${ }^{28}$

Yet demographic characteristics such as ethnic group or gender offer only limited clues to such beliefs, making health professionals elicit them directly. ${ }^{4,6,9,21}$ Discussions with patients and survivors about these beliefs are bound to create emotional discomfort for everybody, but health professionals may dispel much of it by demonstrating a sincere commitment to personalized end-of-life care, showing respect for the beliefs of patients and survivors, ${ }^{7,21,23}$ and accommodating those beliefs whenever possible. ${ }^{2,28}$ The result may be the best of all possible outcomes-sensitive, respectful, and compassionate care for patients and survivors, and rewarding caregiving experiences for health professionals. $^{20,24,25}$

\section{Acknowledgments}

Charles Cavazos provided computer support, and Susan Bagby helped edit the manuscript.

The authors presented these data at the annual meeting of the Southern Region, Society of General Internal Medicine, Atlanta, Georgia, March 2006; the Eighth Annual David C. Thomasma International Bioethics Retreat, Freije Universitat, Amsterdam, the Netherlands, June 2006; the Fifth International Conference on Clinical Ethics and Ethics Consultation, Taichung, Taiwan, March 2009; and the annual conference of the European Association of Centres of Medical Ethics, Venice, Italy, September 2009. The data were also accepted for presentation at the national meeting, Society of General Internal Medicine, Los Angeles, California, April 2006.

This work was supported with resources from the Audie L. Murphy Veterans Administration Medical Center, San Antonio, Texas, but the 
views expressed here do not necessarily reflect the position or policy of the Department of Veterans Affairs or the United States Government.

The following institutions helped fund the research either directly or indirectly: The Department of Veterans Affairs; The John A. Hartford Foundation; the American Federation on Aging Research; and the Mexican-American Medical Treatment Effectiveness Research Center, the Aging Research and Education Center, and the Medical Dean's Office, all at The University of Texas Health Science Center at San Antonio. Funders played no role in the design and conduct of the study; the collection, management, analysis, and interpretation of the data; or the preparation, review, and approval of the manuscript. The authors have no financial conflict of interests.

\section{References}

1. Barclay JS, Blackhall LJ, Tulsky JA. Communication strategies and cultural issues in the delivery of bad news. J Palliat Med. 2007;10(4): 958-977.

2. Orr RD, Marshall PA, Osborn J. Cross-cultural considerations in clinical ethics consultations. Arch Fam Med. 1995;4:159-164.

3. Kagawa-Singer M, Blackhall LJ. Negotiating cross-cultural issues at the end of life: "You got to go where he lives." JAMA. 2001;286(23): 2993-3001.

4. Koenig BA. Understanding cultural difference in caring for dying patients. West J Med. 1995;163(3):244-249.

5. Hallenbeck J, Goldstein MK, Mebane EW. Cultural considerations of death and dying in the United States. Clin Geriatr Med. 1996;12(2): 393-405.

6. Billings JA, Block S. Palliative care in undergraduate medical education: status report and future directions. JAMA. 1997;278(9): 733-738.

7. Carrese JA, Rhodes LA. Bridging cultural differences in medical practice: the case of discussing negative information with Navajo patients. J Gen Intern Med. 2000;15(2):92-96.

8. Krakauer EL, Crenner C, Fox K. Barriers to optimum end-of-life care for minority patients. J Am Geriatr Soc. 2002;50(1):182-190.

9. Crawley LVM, Marshall PA, Lo B, Koenig BA. Strategies for culturally effective end-of-life care. Ann Intern Med. 2002;136(9):673-679.

10. True G, Phipps EJ, Braitman LE, Harralson T, Harris D, Tester W. Treatment preferences and advance care planning at end of life: the role of ethnicity and spiritual coping in cancer patients. Ann Behav Med. 2005;30(2):174-179.

11. McKinley ED, Garrett JM, Evans AT, Danis M. Differences in endof-life decision making among black and white ambulatory cancer patients. J Gen Intern Med. 1996;11(11):651-656.
12. Hanchate A, Kronman AC, Young-Xu Y, Ash AS, Emanuel E. Racial and ethnic differences in end-of-life costs: why do minorities cost more than whites? Arch Intern Med. 2009;169(5): 493-501.

13. Perkins HS, Shepherd KJ, Cortez JD, et al. Exploring chronically ill seniors' attitudes about discussing death and postmortem medical procedures. I Am Geriatr Soc. 2005;53(5):895-900.

14. Hazuda HP, Comeaux PJ, Stern MP, et al. A comparison of three indicators for identifying Mexican Americans in epidemiologic research: methodologic findings in the San Antonio Heart Study. Am J Epidemiol. 1986;123:96-112.

15. Lincoln YS, Guba EG. Naturalistic Inquiry. Newbury Park CA: Sage; 1985:199-202.

16. Braun UK, Beyth RJ, Ford ME, McCullough LB. Voices of African American, Caucasian, and Hispanic surrogates on the burdens of end-of-life decision-making. J Gen Intern Med 2008;23: 267-274.

17. Perkins HS, Cortez JD, Hazuda HP. Cultural beliefs about a patient's right time to die. J Gen Intern Med. 2009;24(11):1240-1247.

18. Baker LM. Information needs at the end of life: a content analysis of one person's story. J Med Libr Assoc. 2004;92(1):78-82.

19. Emanuel EJ, Emanuel LL. The promise of a good death. Lancet. 1998;351(suppl 2):21-29.

20. Steinhauser KE, Clipp EC, McNeilly M, et al. In search of a good death: observations of patients, families, and providers. Ann Intern Med. 2000;132(10):825-832.

21. Quill TE. Initiating end-of-life discussions with seriously ill patients: addressing the "elephant in the room." JAMA. 2000;284(19): 2502-2507.

22. Selph RB, Shiang J, Engelberg R, Curtis JR, White DB. Empathy and life support decisions in intensive care units. J Gen Intern Med. 2008; 23:1311-1317.

23. Larson DG, Tobin DR. End-of-life conversations: evolving practice and theory. JAMA. 2000;284(12):1573-1578.

24. Carr D. A "good death" for whom? Quality of a spouse's death and psychological distress among older widowed persons. J Health Soc Behav. 2003;44(2):215-232.

25. Back AL, Young JP, McCown, et al. Abandonment at the end of life from patient, caregiver, nurse, and physician perspectives. Arch Intern Med. 2009;169(5):474-479.

26. Kirkpatrick JN, Beasley KD, Caplan A. Death is just not what it used to be. Cambr Q Healthc Ethics. 2010;19:7-16.

27. Berger JT, Rosner F, Cassell EJ. Ethics of practicing medical procedures on newly dead and nearly dead patients. J Gen Intern Med. 2002;17:774-778.

28. Dugdale L. The art of dying well. Hast Cen Rep. 2010:40(6):22-24. 